\title{
A CASE OF SARCOMATOUS ENCHONDROMA OF THE PELVIS DURING PREGNANCY.**
}

\author{
By ROBER'T JARDINE, M.D., F.R.S.E., \\ Senior Physician to the Glasgow Maternity Hospital; Examiner in Midwifery to \\ the University of Glasgow.
}

Mrs. H., I-para, aged twenty-nine, was sent into the Maternity Hospital from one of the mining towns near Glasgow. She had been under the care of a medical man for some six weeks, but he sent no history of the case, and did not even condescend to reply to a letter of inquiry sent him some days later. Unfortunately, we rarely receive a word of explanation along with the bad cases sent in.

Mrs. $H$. had been married for nine years. She was now pregnant about seven months for the first time. Her health had been good until she became pregnant, except that she had suffered from pain of an intermittent character in the back of both thighs for two years, particularly during the winter. When three months pregnant, the pain in the thighs became worse, and about a month later the right thigh began to swell. With the onset of the swelling, the pain in the right thigh became much more severe. The swelling gradually increased, and six weeks ago she had to take to bed. Since then the swelling has increased, and at times the pain has been almost unbearable. For some time she has only been able to lie on her left side, and occasionally on her face. A pressure-sore has formed over the left trochanter. She has lost flesh considerably.

Condition on Admission. - The patient was pale and emaciated. She complained of severe pain in the back of the right thigh, and in the right side of the abdomen. The right leg was enormously swollen and œdematous, more especially the thigh and hip. The odema extended up as high as the iliac crest behind and in front. A distinct swelling could be made out in the abdomen above the right iliac crest, almost halfway up to the umbilicus. This swelling was quite distinct from the uterus, and was apparently attached to the ilium. It was particularly tender in the right inguinal region. The uterus was displaced towards the left side, and quite free from the tumour. The head of the child could be palpated lying to the left just above the pelvis. The fotal heart-sounds were easily heard-strong, but rather rapid. On inspecting the labia, they were found to be free of

\footnotetext{
* Read before the Glasgow Obstetrical and Gynæcological Society, March 26 .
} 


\section{I48 Journal of Obstetrics and Gynæcology}

œdema. On attempting to pass a finger into the vagina, the passage was found to be obstructed by a hard globular mass growing from the right of the pelvis. The pain was so great that the attempt had to be given up.

Next day I made a thorough examination under chloroform. The tumour was found to occupy the greater part of the pelvic cavity, growing from the right side, apparently from near the sacroiliac joint. The finger was introduced beyond the mass with difficulty, but the cervix could not be reached. The vaginal mucous membrane was freely movable over the mass, which was soft and almost fluctuant at some points, and at others quite hard. A rectal examination confirmed the observations made per vaginam. A small hard nodule was made out in the anterior uterine wall near the fundus. On passing a catheter into the bladder, the instrument went in obliquely to the left.

My diagnosis was an osteo-sarcoma springing from the right side of the pelvis.

The prognosis was hopeless as regarded the mother. The child was still alive, but, as the pregnancy had barely reached the seventh month, it was very doubtful if an immediate Cæasarean section would give a viable child. I decided to wait until there was a chance of getting a viable child. The tumour, I was quite sure, could not be removed.

The consulting staff of the hospital saw the case. Dr. Cameron quite agreed that it was a sarcoma, and that I ought to wait to give the child a chance. Drs. Reid and Sloan both suggested the possibility of the tumour being a simple one. They agreed with the proposed treatment.

As we failed to get any information from the doctor who had attended her, we questioned the husband to see if we could form any idea of the rate of growth. He informed us that he had last had connection about three months ago, and that for about a month previous to that he had occasionally experienced slight difficulty. This difficulty had not been very marked, and had not been experienced at any time previous to about four months ago. The rate of growth must therefore have been very rapid.

The patient was made as comfortable as possible by the use of opiates to relieve the pain. The bowels were obstinately constipated, and only relieved by aperients and enemata. There was a slight trace of albumen in the urine. It was quite evident that the tumour was steadily growing. The swelling of the leg increased, and the vulva became odematous. As the patient was steadily losing 
ground, it was determined to do Casarean section on the ninth day after admission. Two days before the operation was done, the fotal heart was quite distinct, but it could not be heard on the following evening.

Dr. Reid kindly gave me his advice during the operation, and Dr. Gibson assisted me. The abdominal wall was very œdematous, and the veins in it much engorged. The uterine incision was made in the anterior wall, and the placenta lay beneath it. It is rather curious that, in the last nine or ten sections I have done, I have had to go through the placenta in every one. The child was still-born. Its head showed moulding from the pressure of the tumour. When the placenta and membranes were removed, there was a considerable amount of decidua lining the uterus, and this was swabbed out. On passing the hand into the uterus, it was found that the cervix would allow of drainage, so it was decided to stitch the uterus. A small fibroid tumour was removed from the edge of the incision. The uterus was flabby, but there was very little bleeding. A hypodermic of ergotin was given, and a saline injection under the breast. On examining the tumour, it was found to block the pelvic cavity and to extend up the right side of the abdomen to about the level of the umbilicus anteriorly. The upper part was rounded and quite soft. It was completely retroperitoneal, springing from the side of the pelvis. The broad ligament was opened up by it behind. The operation was finished by stitching the peritoneum and then the abdominal wall.

The patient rallied. from the operation towards the evening, but cardiac failure began to manifest itself, and she died twenty-four hours later. At the time of the operation the temperature was ro $24^{\circ} \mathrm{F}$. It had been normal the evening before.

The post-mortem examination was made by Dr. Carstairs Douglas.

The right labium majus was enormously swollen and engorged, the left little affected. There was also some cedema of the abdomen and groin in the right iliac region. On the right side the abdomen was more prominent in its lower part than on the left, and on palpation it felt distinctly more resistant.

The thorax presented nothing of special note. The heart was small, but apparently healthy. Both lungs were œdematous, and showed evidence of distinct passive congestion in their lower and posterior portions.

On opening the abdomen and carrying the incision through the wound, some serous fluid of a straw colour escaped. The parietes 


\section{50 Journal of Obstetrics and Gynæcology}

at the wound were rather soft, pulpy, and œedematous. There was no pus present. There was a slight adhesion between the uterus and the parietes. The peritoneum appeared quite normal. The uterus was lying well up in the abdomen, the fundus as high as the umbilicus. On its anterior and upper part was a firmly-sutured wound about 5 inches in length. The tubes and ovaries were healthy; the right ovary was slightly enlarged. The bladder was moderately full.

On reflecting the abdominal parietes, it was at once apparent that the right half of the false and true pelvis was filled with a large pathological mass (Fig. I). This was rounded and nearly smooth on its superior, anterior, and inner aspects. The upper part was of a bluish tint, and felt soft and boggy. Its lower part was firmer and more flesh-tinted. It lay beneath the peritoneum on the posterior abdominal wall and pelvis. The dimensions were as follows:

I. Superiorly it rose to the tip of the eleventh rib and slightly above the umbilicus (about the level of the second lumbar vertebra).

2. Anteriorly it grew forwards sufficiently to make a prominence in the right iliac region.

3. Internally it reached the middle line at the level of the promontory of the sacrum. Above this it gradually receded from the middle line of the body, while in the true pelvis, near the outlet, it rather exceeded this limit.

4. Posteriorly and externally it was continuous with the pelvic wall.

5. Inferiorly it was found, on removing the whole pelvis, that it had grown down under the pelvic arch; that it had incorporated in its substance practically all the upper part of the ischium and of the pubis and the ilium near the acetabulum. It had grown out of the pelvis also at the great sacro-sciatic notch, and had so eaten through the bones just behind the acetabulum that the ilium here had become quite detached from the ischium and pubis. The lower part of the growth was more osseous than the upper, and contained many large spaces, some of them full of blood. It was very fragile, and easily crumbled. There was no distinct demarcating line of tissue to circumscribe it, but it projected in an irregular manner into the tissues of the thigh in its upper part. One or two small glands were enlarged along the right Poupart's ligament. Some enlarged retroperitoneal glands were also found, No metastatic growths were found. The right ureter, in its course to the bladder, was stretched over the tumour.

The spleen, kidneys, and other abdominal organs showed nothing of interest. The liver was large, pale, and fatty. 


\section{Jardine: Sarcomatous Enchondroma of the Pelvis I 5 I}

The entire pelvis and tumour was removed, and I now show it to you, and also an admirable drawing which Dr. Lindsay kindly made. To the left is seen the sutured uterus with the bladder below it. The tumour mass projects through the right side of the pelvis. The dotted line indicates the upper limit of the tumour at the time of operation.

The following is the report of the microscopic examination of the tissues made by Dr. Douglas:

'The microscopic examination of the growth showed it to be composed almost entirely of large, rapidly-growing cartilage cells, with here and there small groups of cells suggestive of sarcomatous

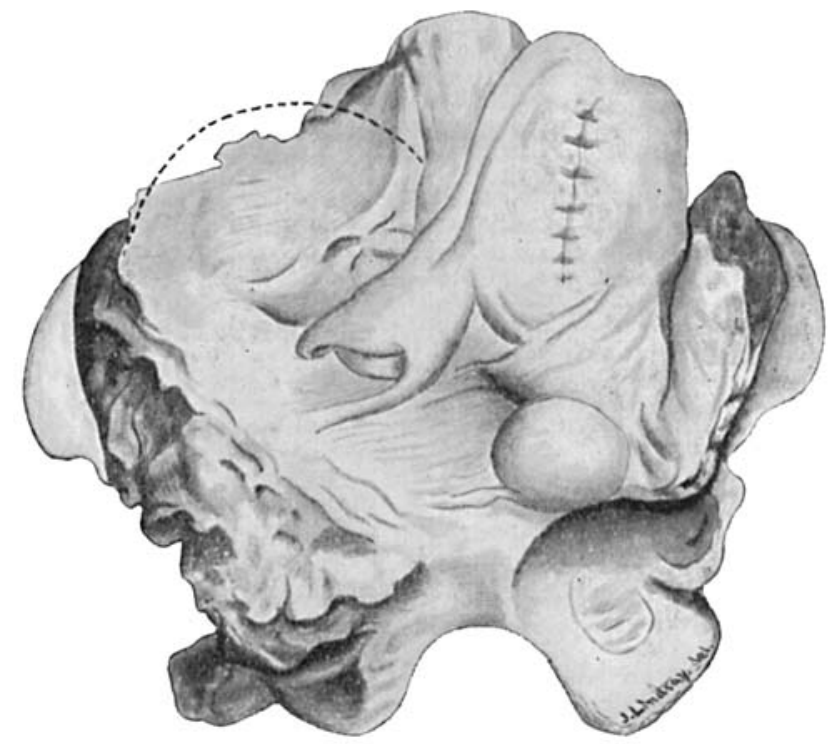

Fig. I.-ThF Pelvis after Removal from the Body.

The growth lies to the right, the sutured uterus to the left.

degeneration. There were also cysts at places, so it may be an ordinary enchondroma with cystic changes, or with sarcomatous degeneration, or both.'

It is impossible to decide when this tumour first began to grow. It may have been there before conception, and the sciatic pains would point to the nerve having been affected during the last two years. If it was there at the beginning of the pregnancy, it is quite certain that its rate of growth became very rapid after impregnation. The growth may have been simple to begin with, but there is no doubt of its malignant character finally, although it is difficult to demonstrate sarcomatous cells in it.

I regret that I did not operate a couple of days sooner, as there 


\section{52 Journal of Obstetrics and Gynæcology}

would then have been a slight chance of saving the child's life, but we had no warning of its impending death. I do not know what caused its death.

I am deeply indebted to Dr. Campbell Maclure for the careful notes of the case; to Dr. Lindsay for his admirable drawing; to Dr. Douglas for the pathological report; and also to Drs. Reid and Gibson for their assistance at the operation. 